\title{
Ortaokul Öğrencilerinin E-Okuryazarlığa İlişkin Tutumlarının Çeşitli Değişkenler Açısından İncelenmesi*
}

\author{
Burcu BİLGE ${ }^{1}$ \\ Bahadir KILCAN²
}

Makale Bilgisi

Alınma Tarihi

16.09.2020

Kabul Tarihi

21.10.2020

Yayınlanma

Tarihi

30.12.2020
Özet

$\mathrm{Bu}$ çalışmanın amacı ortaokul öğrencilerinin e-okuryazarlık tutumlarını çeşitli değişkenler açısından incelenmektir. Araştırmada betimsel araştırma desenlerinden biri olan tarama modeli kullanılmıştır. Araştırmanın çalışma grubunu, Konya ili Kulu ilçesinde 2017-2018 eğitim-öğretim yılında öğrenim gören 5, 6, 7 ve 8. Sınıf, 451'i kız, 456'sı erkek olmak üzere toplamda 907 ortaokul öğrencisi oluşturmaktadır. Elde edilen verilerin istatiksel analizleri SPSS paket programının yardımıyla t-testi, Welch testi ve tek yönlü Varyans Analizi (ANOVA) kullanılarak yapılmıştır. Araştırma sonucunda öğrencilerin cinsiyet değişkenine göre e-okuryazarlık tutum puanları ortalamalarında erkek öğrenciler lehine anlamlı bir farklılık bulunmuştur. Öğrencilerin sınıf seviyelerinin arttıkça e-okuryazarlık tutumlarında da olumlu yönde artış olduğu görülmüş, evinde bilgisayar olan, kişisel mail adresi olan, evinde internet bağlantısı olan ve akıllı telefonu olan öğrencilerle olmayanlar arasında farklılıklar gözlenmiş ve bu öğrencilerin e-okuryazarlık tutumlarının olumlu yönde artış gösterdiği saptanmıştır. Öğrencilerin e-devlet kullanma durumlarına göre e-okuryazarlığa ilişkin tutumlarında herhangi bir farklılaşmanın olmadığı görülmüştür. İnternette geçirilen zaman arttıkça öğrencilerin e-okuryazarlığa ilişkin tutumlarının da olumlu olduğu görülmüştür. İnternet kullanım amacına göre interneti sosyal medya için kullanan katılımcıların interneti oyun, bilgi ve ödev amacıyla kullananlara göre; oyun ve bilgi için kullananların da ödev için kullananlara göre e-okuryazarlığga ilişkin tutumlarının daha olumlu olduğu sonucuna ulaşılmıştır. Çalışma süresince elde edilen verilere dayalı olarak da araştırmacılara yönelik bazı önerilerde bulunulmuştur.

Anahtar Kelimeler: Ortaokul öğrencileri, E-okuryazarlık, Tutum

\footnotetext{
${ }^{*} \mathrm{Bu}$ araştırma “Ortaokul Öğrencilerinin E-Okuryazarlığa İlişkin Tutumlarının Çeşitli Değişkenler Açısından İncelenmesi" adlı yüksek lisans tez çalışmasından üretilmiştir.

${ }^{1}$ Öğretmen, Milli Eğitim Bakanlığı, Türkiye, gulbudakburcu@gmail.com. ORCID ID: 0000-0001-6323-4777

2 Doç. Dr., Gazi Üniversitesi, Gazi Eğitim Fakültesi, Türkçe ve Sosyal Bilimler Eğitimi Bölümü, Türkiye, bahadir@gazi.edu.tr. ORCID ID: 0000-0003-0646-1804
}

Atıf künyesi: Bilge, B. ve Kılcan, B. (2020). Ortaokul öğrencilerinin e-okuryazarlığa ilişkin tutumlarının çeşitli değişkenler açısından incelenmesi. Journal of Innovative Research in Social Studies. 3(2), 114-130. 


\section{Analysis of Secondary School Students Attitude towards E-Literacy in terms of Various Variables}

\section{Article Info \\ Abstract}

The aim of this survey is to analyze the attitude of secondary school students towards e-literacy in terms of various variables. A descriptive survey method is used in this survey. The study group consists of 451 girls and 456 boys a total of 907 students, who reside in Kulu District of Konya Province and attend 5th 6th -7th and 8th grades. The statistical analysis of the acquired data is carried out with the help of T-test, Welch Test and One-Way Analysis of Variance (ANOVA) with the help of SPSS software package. As a result of the survey, according to gender variable of the students there is a substantive difference found out in the average points of e-literacy attitude in favour of boy students.

Received It is the students' attitudes towards e-literacy that they progress in direct 16.09.2020 proportion with their grade levels. Students who possess a computer, a Accepted smartphone, a personal e-mail address and an internet connection differ from 21.10.2020 those who don't and their attitudes is found out to be advancing in favour of eliteracy. It is also found out that students' use of e-state does not cause a change in their attitudes towards e-literacy. As the time spent on the internet increases

Published Online

30.12.2020 the students' attitudes towards e-literacy is found out to be increasing proportionally. It is deduced that those who use the internet for social media has better attitudes towards e-literacy when compared to those who use it for game, information and homework assignments, meanwhile, those who use the internet for games and information has better attitudes towards e-literacy when compared with those who use it only for homework assignments. Hinged upon the data acquired throughout the study, various suggestions are made for the researchers.

Keywords: Secondary School students, E-Literacy, Attitudes 


\section{GíRiş}

Hızla gelişen teknoloji, günlük hayatta ve eğitim hayatında birçok yenilik ve değişime neden olmaktadır. İnsanların bu duruma ayak uydurabilmesi için teknolojinin sunduğu değişimlerden ve yeniliklerden haberdar olmaları gerekmektedir. Fakat sadece bu yeniliklerden haberdar olmak insan yaşamını devam ettirmede yeterli olmamaktadır. Bu yeterliği sağlamak ancak teknolojinin insanlara sundukları hakkında bilgi sahibi olmakla birlikte bunları günlük hayatta kullanılabilir hale gelmekle mümkündür. Çünkü küreselleşen dünya insanlardan aktif, üretken, birçok bilgi ve beceriyle donatılmış ve bunları kullanan bireyler olmalarını istemektedir.

Günümüz insanı doğuşundan itibaren gerek aile içerisinde gerekse eğitim sürecinde birçok bilgiyle karşılaşıp ona sahip olmaktadır. Eskiden, eğitim sürecinde yer alan bireylere bilgiler aktarılır, bireylerin bu bilgileri öğrenmeleri istenir ve bu durum yeterli olarak nitelendirilirdi. Şimdilerde ise yeni eğitim sistemleri, bireylerin bilgileri öğrenmelerini yeterli görmemekte, kazanılan bilgilerin günlük hayatta kullanılması gerekliliği üzerine odaklanmaktadır. Aslında benimsenen sistem bireylerin birer bilgi deposu olmaktansa onların bilgiye kendilerinin ulaşmalarını, bilgiyi oluşturmalarını ve günlük yaşamlarında da etkili bir şekilde uyarlayıp kullanmaların istemektedir. Benimsenen sistem, sadece bunlarla yetinmeyip bireylerin karşısına çıkabilecek bilgilerin değişeceğini, yeni bilgi ve becerilerin ortaya çıkacağını, bireylerin sadece eğitim kademelerinde öğrendikleri bilgilerle değil, örgün eğitim sisteminden ayrıldıktan sonra da kendilerini geliştirmelerinin gerekliliği anlayışından hareketle hayat boyu öğrenmeyi temel almaktadır.

Bireylerin hayatlarındaki değişen koşullara uyum sağlamaları konusu onların birtakım kavramlarla da yüzleşmesini gerekli kılmaktadır. Bu kavramlardan biri okuryazarlıktır. Okuryazarlık kavramının tanımı ilk olarak 1950'li yıllarda yapılmıştır. Yapılan tanım, bugünün koşulları, teknolojisi ve bilgi birikimi dikkate alındığında oldukça sınırlı kalmaktadır. O dönemki tanımdan okuryazarlığın sadece temel okuma yazma becerisi olarak görüldüğü anlaşılmaktadır. Fakat daha sonra yapılan araştırmalar okuryazarlığın okuma yazma becerisinin yanında, okuduğunu anlama, yazıyla kendini ifade etme, zihinsel becerileri geliştirme gibi daha geniş bir çeşitlilikte ele alınması gerektiği gerçeğini ortaya koymuştur (Aş1c1, 2009, s. 12; Karatekin, 2013). Gelişen teknolojiklerden ve değişen sosyal, toplumsal, ekonomik vb. olaylardan etkilenen okuryazarlık kavramı hakkında, geçmişten günümüze pek çok tanımlamalar yapılmıştır (Güneş, 1994).

Okuryazarlık hayat boyu devam eden, dinamik, birçok bilgi ve beceriyi içeren, bu bilgi ve becerileri yaşama aktarmaya yarayan (Yılmaz, 1989, s. 48) bir kavram olarak tanımlandığı gibi sosyal olarak meydana getirilmiş iletişim ve temsil sistemlerini etkili bir şekilde kullanma ile ilgili yeterliklerin kazanılması (Altun, 2003; Kellner, 2001, s. 68-69), bireyin duygu ve düşüncelerini ifade etmesi, başkalarını anlaması ve kendi bilgi ve becerilerini kullanması (Aşıc1, 2009, s. 12) olarak da tanımlanmaktadır.

Yukarıdaki tanımlamalardan da anlaşılacağı üzere okuryazarlığın birçok işlevinden bahsetmek mümkündür. Toplumların ve teknolojinin değişimi ile genişleyen bu işlevler, toplumun değişen koşullarına ayak uydurabilmek için yeni okuryazarlıkların ortaya çıkmasına zemin hazırlamaktadır. Farklı okuryazarlıkların ortaya çıkması bireylerin yeni bilgi ve becerilerle donanmasına katkı sağlarken toplumsal uyum ve gelişmeyi de beraberinde getirmektedir (Altun, 2005, s. 8-9). 
Teknolojideki yaşanan katlanarak artış, onunla ilgili olan okuryazarlıkların da çeşitlenerek doğmasına imkân tanımaktadır. Bunlardan birisi, teknoloji sayesinde birçok işlemin elektronik ortamda yapılmasının sonucu olarak ortaya çıkmış olan enformasyon tabanlı okuryazarlık (e-okuryazarlık'tır. Ancak bu okuryazarlık geleneksel anlamda algılanan okuryazarlığın bir alternatifi olarak değil ancak tamamlayıcısı olarak görülmeli ve anlamlandırılmalıdır (Reinking, McKenna, Labbo, \& Kieffer, 1997; Tuman, 1994).

E- okuryazarlık genel manada sosyal ağlara erişim ve onlarda bilgi paylaşımına olanak sağlayan bilgisayar ve iletişim teknolojilerinin bilinçli kullanımına yönelik sosyal ve yerel uygulamaları tanımlamak için kullanılmaktadır (Kılcan \& Çepni, 2017, s. 343). Bireylerin elektronik ortamları aktif ve bilinçli bir şekilde kullanmalarını sağlamayı amaç edinen (Altun, 2005, s. 12) e-okuryazarlık, internetin insan hayatına girmesiyle beraber ticari ve sosyal hayatta "e" ön ekli birçok yeni kavramın (e- devlet, e-hukuk e-ticaret, e-toplum) oluşmasına da zemin hazırlamıştır (Aytaş \& Kaplan, 2017, s. 301).

Bireylerin e-okuryazar olarak nitelendirilebilmeleri için elektronik ortamlarda bilgisayar, cep telefonu vb. mesajlarını düzenleyebilmeleri, kullanabilmeleri ve paylaşabilmeleri, interneti kullanabiliyor olmaları, temel teknik becerileri bilmeleri ve aynı zamanda bilgisayar okuryazarı olmaları gerekmektedir (HEFCE, 2004; Kılcan \& Çepni, 2017, s. 344; Sakall1, 2015, s. 70).

E-okuryazarlık bazen teknoloji okuryazarlığı ve dijital okuryazarlık gibi kavramlarla karıştırılabilmektedir. Bu kavramlara baktığımızda; dijital okuryazarlık, dijital olarak nitelendirilen ortamlardaki bilgileri anlamlandırma, bunlardan yararlanma ve dijital problemleri çözebilme (Gilster, 1997) işidir. Bunları yaparken bireyler internette araştırma yapma, hiper metinlerden yararlanma, bilgiler arasında ilişki kurma ve içeriği değerlendirme gibi dört yeterliği de yerine getirirler. Bunun yanında e-okuryazarlığın ise daha çok bilgisayar ve internet odaklı olduğu görülmektedir. E-okuryazarlık daha çok elektronik metinler üzerine kuruludur (Yiğit, 2013, s. 258). Bu metinler, dijital olan veya dijital olmayan ortama aktarılmışlardır. Aynı zamanda buradaki metinlere ses, görüntü, sesli görüntü, animasyonlar da eklenebilmektedir. Bu sayede elektronik metinler sözel, görsel ve işitsel bir boyuta taşınmaktadır. İşte e-okuryazarlık bu metinlere yönelik becerileri kapsamaktadır. Bütün bunların yanında teknoloji okuryazarlığı ise daha geniş bir kavram olarak yukarıda ifade edilen okuryazarlıkların (dijital okuryazarlık, e-okuryazarlık) tümünü kapsamaktadır. Teknoloji okuryazarlığı, kelime işlemcisi ve hesap tablosu gibi temel araçlarla nasıl çalışılacağını bilme dâhil, doğal ortam dışındaki her şeye dair bilgi, beceri ve tutumların bütünü olarak tanımlanabilmektedir (Kılcan \& Çepni, 2017, s. 341; Yiğit, 2013, s. 256).

Günümüzde bireylerin kendi sorumluluklarını yerine getirmelerine, diğer bireylerle ve devletle olan ilişkilerini düzenlemelerine fırsat tanıyan e-okuryazarlık, vatandaşların bir tıkla e-devlet üzerinden kendilerine ait birçok bilgiye kısa sürede ulaşabilmelerine, sosyal medya üzerinden tanıdıklarıyla kolaylıkla iletişim kurabilmelerine, eğitim ortamında öğrencilerin ders içeriklerine, notlarına, devamsızlık durumlarına kolayca erişebilmelerine de olanak sağlamaktadır. Bu sayılan olanaklar e-okuryazarlığın iyi bir vatandaş, iyi bir veli, iyi bir öğretmen olmak için önemli sayılabilecek beceriler arasında yerini almasının gerekçesi olarak görülebilir (Kılcan \&Çepni, 2017, s. 345).

$\mathrm{Bu}$ bağlamda toplumu oluşturan bireylerin genç yaştan itibaren e-okuryazar olarak nitelendirilebilecek şekilde donanıma sahip olmaları hem toplumun hem de onu oluşturan bireylerin enformasyon çağına uyumunda önemli bir kazanım olarak görülebilir. Dolaysıyla 
bu kazanıma ulaşmak, bireylere erken yaşlardan itibaren eğitim kurumları vasıtasıyla eokuryazarlığın kazandırılmasını önemli kılmaktadır. Bireylerin e-okuryazar olarak topluma kazandırmak sosyal bilgiler dersi ile mümkündür. Çünkü dersin öğretim programında dijital teknolojideki gelişmelere bağlı olarak vatandaşlık hak ve sorumlulukları ile ilgili dijital yeni durumların (dijital vatandaşlık, e-devlet, sanal ticaret, sosyal medya vb.) ve birtakım dijital sorunların (dijital bölünmüşlük, kimlik hırsızlı̆̆ı, kişisel bilginin gizliliği, siber dolandırıcılık, siber zorbalık vb.) altı çizilmekte ve bunlara karşı öğrencilerin dijital vatandaşlık yeterliliklerinin geliştirmesi gerektiği (MEB, 2018) vurgulanmaktadır. Öğrencilerin yeterliklerinin geliştirilmesinde, öncelikle öğrencilerin bu yeterliklere ilişkin tutumlarını belirlemek önemli paya sahiptir. Çünkü bir şeye ilişkin tutum, o şeyin kazanılmasına ne denli istekli olunduğuyla ilgili ipuçları vermektedir. Buradan hareketle mevcut araştırma, ortaokul düzeyindeki öğrencilerin e-okuryazarlığa ilişkin tutumlarının çeşitli değişkenler açısından belirlemek amacıyla gerçekleştirilmiştir.

$\mathrm{Bu}$ amaçlar doğrultusunda katılımcıların e-okuryazarlığa ilişkin tutumlarının onların cinsiyetlerine, sinıf düzeylerine, evlerinde bilgisayar ve internet bulunma, maile adresine ve akıllı telefona sahip olma, internetten alışveriş yapma, e-devlet kullanma, internette geçirilen zaman durumlarına ve interneti kullanma amaçlarına göre farklılaşıp farklılaşmadığına cevap aranmıştır.

\section{YÖNTEM}

\section{Araştırmanın Modeli}

Çalışmada ortaokul öğrencilerinin e-okuryazarlığa ilişkin tutumlarını çeşitli değişkenlere göre belirleyebilmek amacıyla ilişkisel tarama modeli temel alınarak gerçekleştirilmiştir. Karasar (2015, s. 77) bu yöntemin, araştırmaya konu olan bir şeyin var olan koşullar altında, herhangi bir etkide bulunulmadan değerlendirmeye olanak tanımasından bahsederken; Büyüköztürk, Kılıç-Çakmak, Akgün, Karadeniz ve Demirel (2010, s. 16) ise yukarıdaki ifadeye ek olarak yöntemin, geniş kitlelere uygulama imkânı sunmasından dolayı sıklıkla kullanıldığına dikkat çekmişlerdir.

\section{Katılımcilar}

Araştırmanın katılımcı grubunu 2017-2018 eğitim öğretim döneminde Konya'nın Kulu ilçesinde amaçsal örnekleme yöntemlerinden kolay ulaşılabilir örnekleme yöntemi uygun olarak seçilen ortaokul düzeyindeki 907 (Erkek 456- Kız 451) öğrenci oluşturmaktadır. Örneklem seçimindeki kolay ulaşılabilirlik birinci araştırmacının belirtilen ilçede görev yapıyor olması ve uygulama yapılan okullardaki idareciler ve öğretmenlerle tanışıyor olmasıyla açıklanabilir.

\section{Veri Toplama Araci}

Çalışmada veri toplama aracı olarak katılımcılara ait demografik birtakım bilgileri belirlemeye yarayan kişisel bilgi formu ile Kılcan ve Gülbudak (2019) tarafından geliştirilen EOkuryazarlığa Yönelik Tutum Ölçeği (EYTÖ) kullanılmıştır. Kullanılan ölçek 3'lü Likert tipinde 21 maddeden oluşmakta ve tek faktörden meydana gelmektedir. Ölçeğe ait tek faktör 
ölçeğin toplam varyansının \%30,97'sini açıklamakta ve burada yer alan maddelerin faktör yükleri 0.45 ile 0.71 arasında değişmektedir.

\section{Verilerin Toplanması}

$\mathrm{Bu}$ aşamada ilk önce katılımclara veri toplama aracı dağıtılmış ve araştırmanın ne amaçla yapıldığı hakkında bilgiler sunulmuştur. Daha sonra çalışmanın nasıl yapılacağı ile ilgili veri toplama aracında yer alan yönerge okunarak katılımcılar bilgilendirilmiştir. Uygulama sonrasında katılımcılardan elde edilen 1000 form içinden eksik işaretlemelerin, boş bırakılanların olduğu 93 adet form tespit edilerek araştırma kapsamı dışına çıkarılmış, böylelikle 907 adet form araştırmanın veri setini oluşturmuştur.

\section{Verilerin Analizi}

Katılımcılardan elde edilen veri setinin analizi için SPSS paket programından yararlanılmıştır. Verilerinin normal dağılım gösterdiği varsayılan araştırmada yapılan istatistiki analizler sonucunda, varyansların homojenlik gösterdiği durumlarda bağımsız gruplar için $t$ testi ve tek yönlü Varyans Analizi, homojenlik göstermediğinde ise Welch testi kullanılmıştır. Anlam farklılı̆̆ı olan değişkenlerin, anlamlılığını tespit etmede post hoc testlerinden Scheffe ve Tamhane testleri kullanılmıştır.

\section{BULGULAR}

Araştırmanın bulguları kapsamında katılımcıların e-okuryazarlığa ilişkin tutumlarının, onların "cinsiyet, sınıf; bilgisayarın, mail adresinin, internet bağlantısının, e-devlet hesabının, akıllı telefonun olup olmaması; internetten alışveriş yapılıp yapılmaması, internette geçirilen zaman, interneti kullanım amacı" gibi değişkenlere göre farklılı̆̆ını saptamak amacıyla istatistikî bilgilere yer verilmiştir.

Tablo 1.

Katılımcıların E-okuryazarlığa İlişkin Tutumlarının Cinsiyet Değişkenine Göre t-testi Sonuçları

\begin{tabular}{lcrrrrl}
\hline Cinsiyet & $\mathbf{N}$ & $\overline{\boldsymbol{X}}$ & $\mathbf{S}$ & sd & $\mathbf{t}$ & $\mathbf{p}$ \\
\hline K1z & 451 & 49,34 & 8,00 & & & \\
\hline Erkek & 456 & 50,68 & 7,77 & & 2,556 &, 011 \\
\hline
\end{tabular}

Tablo 1'e göre katılımcıların e-okuryazarlığa ilişkin tutum toplam puanları ile cinsiyet değişkeni arasında anlamlı bir farklılığın olduğu görülmektedir $\left[t_{(905)}=2,556 ; p<, 05\right]$. Kız öğrencilerin e-okuryazarlığa ilişkin tutum puanları ortalaması $\left(\bar{X}_{=49,34)}\right.$ iken, erkeklerin eokuryazarlığa ilişkin tutum puanları ortalaması $(\bar{X}=50,68)^{\prime}$ dir. Aradaki fark istatistiksel açıdan anlamlıdır. Bu bulgu katılımcıların cinsiyetlerinin e-okuryazarlığa yönelik tutumlarında farklılaşmaya neden olduğu şeklinde yani erkek öğrencilerin e-okuryazarlığa ilişkin tutumlarının kız öğrencilere göre daha olumlu olduğu şeklinde yorumlanabilir.

Tablo 2.

Katılımcıların E-okuryazarlığa İlişkin Tutumlarının Sınıf Düzeyi Değişkenine Göre Farklılı̆̆ı için Welch Testi Sonuçları 


\begin{tabular}{|c|c|c|c|c|c|c|}
\hline Değişken & & & & $\mathbf{N}$ & $\bar{X}$ & $\mathrm{~S}$ \\
\hline \multirow{8}{*}{ Sınıf düzeyi } & \multicolumn{3}{|c|}{ 5.sinif } & 255 & 48,80 & 7,29 \\
\hline & \multicolumn{3}{|c|}{ 6.sinif } & 284 & 49,46 & 8,14 \\
\hline & \multicolumn{3}{|c|}{ 7.sinif } & 197 & 49,80 & 8,56 \\
\hline & \multicolumn{3}{|c|}{ 8.sinif } & 171 & 52,97 & 6,89 \\
\hline & \multicolumn{2}{|r|}{ İstatistik } & sd1 & $\mathrm{sd} 2$ & $\mathrm{p}$ & $\begin{array}{l}\text { Fark } \\
\text { Tamhane }\end{array}$ \\
\hline & \multirow{3}{*}{ Welch } & \multirow{3}{*}{13,210} & \multirow{3}{*}{3} & \multirow{3}{*}{470,644} & \multirow{3}{*}{,000 } & $8-5$ \\
\hline & & & & & & $8-6$ \\
\hline & & & & & & $8-7$ \\
\hline
\end{tabular}

Tablo 2'ye göre katılımcıların e-okuryazarlığa ilişkin tutum toplam puanları ile sınıf düzeyi değişkeni arasında anlamlı bir farklılığın olduğu görülmektedir $\left[F_{\text {(welch })}=13,210 ; p<, 05\right]$. Bu farklılığın hangi gruplar arasında olduğunu öğrenmek amacıyla Tamhane testi yapılmıştır. Bu sonuçlara göre 8. Sınıfta öğrenim gören katılımcıların e-okuryazarlığa ilişkin tutum toplam puanları ortalaması $(\overline{\boldsymbol{X}}=52,97)$ ile 5. sınıfta öğrenim gören katılımcıların e-okuryazarlığa ilişkin tutum toplam puanları ortalaması $(\bar{X}=48,80)$, 6. sinıfta öğrenim gören katılımcıların eokuryazarlığa ilişkin tutum toplam puanları ortalaması $(\bar{X}=49,46)$, 7. sınıfta öğrenim gören katılımcıların e-okuryazarlığa ilişkin tutum toplam puanları ortalaması $(\overline{\boldsymbol{X}}=49,80)$ arasında 8. sınıfta öğrenim gören katılımcıların lehine anlamlı farklılık bulunmuştur. Bu bulgu; katılımcıların sınıf düzeyleri arttıkça onların e-okuryazarlığa ilişkin tutumlarının da daha olumlu olduğu şeklinde yorumlanabilir.

Tablo 3.

Katılımcıların E-okuryazarlı̆̆a İlişkin Tutumlarının Bilgisayara Sahip Olma Değişkenine Göre t-testi Sonuçları

\begin{tabular}{|c|c|c|c|c|c|c|}
\hline $\begin{array}{l}\text { Evinizde Bilgisayar } \\
\text { Var mı? }\end{array}$ & $\mathbf{N}$ & $\bar{X}$ & $S$ & sd & $\mathbf{t}$ & p \\
\hline Evet & 450 & 51,74 & 7,48 & \multirow{2}{*}{905} & \multirow{2}{*}{6,704} & \multirow{2}{*}{, 000} \\
\hline Hayır & 457 & 48,31 & 7,96 & & & \\
\hline
\end{tabular}

Tablo 3' e göre katılımcıların e-okuryazarlığa ilişkin tutum toplam puanları ile bilgisayara sahip olma değişkeni arasında anlamlı bir farklılığın olduğu görülmektedir $[\mathrm{t}(905)=6,704 ; \mathrm{p}<, 05]$. Bilgisayarı olan öğrencilerin e-okuryazarlığa ilişkin tutum puanları ortalaması $(\bar{X}=51,74)$ iken, olmayanların e-okuryazarlığa ilişkin tutum puanları ortalaması aritmetik ortalaması $\left(\bar{X}_{=48,31)}\right)^{\prime}$ dir. Aradaki fark istatistiksel açıdan anlamlıdır. Bu bulgu katılımcıların bilgisayara sahip olma durumlarının e-okuryazarlığa ilişkin tutumlarında farklılaşmaya sebep olduğu şeklinde yani bilgisayarı olan öğrencilerin e-okuryazarlığa ilişkin tutumlarının olmayanlara göre daha olumlu olduğu şeklinde yorumlanabilir.

\section{Tablo 4 .}

Katılımcıların E-okuryazarlı̆̆a İlişkin Tutumlarının Mail Adresine Sahip Olma Değişkenine Göre ttesti Sonuçları 


\begin{tabular}{|c|c|c|c|c|c|c|}
\hline Mailiniz Var mı? & $\mathbf{N}$ & $\bar{X}$ & $\mathrm{~S}$ & sd & $\mathbf{t}$ & $\mathbf{P}$ \\
\hline Evet & 322 & 53,68 & 6,47 & \multirow{2}{*}{-905} & \multirow{2}{*}{11,023} & \multirow{2}{*}{,000 } \\
\hline Hayır & 585 & 48,00 & 7,91 & & & \\
\hline
\end{tabular}

Tablo 4' e göre katılımcıların e-okuryazarlığa ilişkin tutum toplam puanları ile mail adresine sahip olma değişkeni arasında anlamlı bir farklılığın olduğu görülmektedir $\left[\mathrm{t}_{(905)}=11,023\right.$; $\mathrm{p}<, 05]$. Mail adresi olan öğrencilerin e-okuryazarlığa ilişkin tutum puanları ortalaması $\left(\bar{X}_{=53,68)}\right.$ iken, olmayanların e-okuryazarlığa ilişkin tutum puanları ortalaması aritmetik ortalaması $(\bar{X}=47,99)^{\prime}$ dur. Aradaki fark istatistiksel açıdan anlamlıdır. Bu bulgu katılımcıların mail adresine sahip olma durumlarının e-okuryazarlığa ilişkin tutumlarında farklılaşmaya sebep olduğu şeklinde yani mail adresi olan öğrencilerin e-okuryazarlığa ilişkin tutumlarının olmayanlara göre daha olumlu olduğu şeklinde yorumlanabilir.

Tablo 5.

Katılımcıların E-okuryazarlı̆̆a İlişkin Tutumlarının İnternete Sahip Olma Değiş̧kenine Göre t-testi Sonuçları

\begin{tabular}{|c|c|c|c|c|c|c|}
\hline $\begin{array}{l}\text { Evinizde İnternet Var } \\
\text { mı? }\end{array}$ & $\mathbf{N}$ & $\bar{X}$ & $S$ & sd & $\mathbf{t}$ & $\mathbf{p}$ \\
\hline Evet & 530 & 51,20 & 7,45 & \multirow{2}{*}{905} & \multirow{2}{*}{5,439} & \multirow{2}{*}{,000 } \\
\hline Hayır & 377 & 48,34 & 8,24 & & & \\
\hline
\end{tabular}

Tablo 5'e göre katılımcıların e-okuryazarlığa ilişkin tutum toplam puanları ile internet ağına sahip olma değişkeni arasında anlamlı bir farklılığın olduğu görülmektedir $\left[\mathrm{t}_{(905)}=5,439 ; \mathrm{p}<, 05\right]$. İnternet ağı olan öğrencilerin e-okuryazarlığa ilişkin tutum puanları ortalaması $(\bar{X}=51,20)$ iken, olmayanların e-okuryazarlığa ilişkin tutum puanları ortalaması aritmetik ortalaması $\left(\bar{X}_{=48,34)}\right)^{\prime}$ ür. Aradaki fark istatistiksel açıdan anlamlıdır. Bu bulgu katılımcıların internet ağına sahip olma durumlarının e-okuryazarlığa ilişkin tutumlarında farklılaşmaya sebep olduğu şeklinde yani internet ağı olan öğrencilerin e-okuryazarlığa ilişkin tutumlarının olmayanlara göre daha olumlu olduğu şeklinde yorumlanabilir.

\section{Tablo 6 .}

Katılımcıların E-okuryazarlığa İlişkin Tutumlarının İnternetten Alışveriş Yapma Durumu Değişkenine Göre t-testi Sonuçları

\begin{tabular}{|c|c|c|c|c|c|c|}
\hline $\begin{array}{l}\text { İnternetten Alışveriş } \\
\text { Yapma }\end{array}$ & $\mathbf{N}$ & $\bar{X}$ & $S$ & sd & $\mathbf{t}$ & $\mathrm{p}$ \\
\hline Evet & 279 & 53,61 & 7,01 & \multirow{2}{*}{905} & \multirow{2}{*}{9,970} & \multirow{2}{*}{,000 } \\
\hline Hayır & 628 & 48,41 & 7,76 & & & \\
\hline
\end{tabular}

Tablo 6' ya göre katılımcıların e-okuryazarlığa ilişkin tutum toplam puanları ile internetten alış veriş yapma durumu değişkeni arasında anlamlı bir farklılığın olduğu görülmektedir $\left[\mathrm{t}_{(905)}=9,970 ; \mathrm{p}<, 05\right]$. İnternetten alışveriş yapan öğrencilerin e-okuryazarlığa ilişkin tutum puanları ortalaması $\left(\bar{X}_{=53,61)}\right.$ iken, yapmayanların e-okuryazarlığa ilişkin tutum puanları 
ortalaması aritmetik ortalaması $(\bar{X}=48,41)^{\prime}$ dir. Aradaki fark istatistiksel açıdan anlamlıdır. Bu bulgu katılımcıların internetten alışveriş yapma durumlarının e-okuryazarlığa ilişkin tutumlarında farklılaşmaya sebep olduğu şeklinde yani internetten alışveriş yapanların eokuryazarlığa yönelik tutumlarının yapmayanlara göre daha olumlu olduğu şeklinde yorumlanabilir.

Tablo 7.

Katılımcıların E-okuryazarlığa İlişkin Tutumlarının E-Devlet Kullanma Durumu Değişkenine Göre ttesti Sonuçları

\begin{tabular}{|c|c|c|c|c|c|c|}
\hline E-Devlet Kullanma & $\mathbf{N}$ & $\bar{X}$ & $\mathrm{~S}$ & sd & $t$ & $\mathrm{p}$ \\
\hline Evet & 81 & 51,59 & 7,74 & \multirow{2}{*}{-905} & \multirow{2}{*}{1,888} & \multirow{2}{*}{,059 } \\
\hline Hayır & 826 & 49,86 & 7,91 & & & \\
\hline
\end{tabular}

Tablo $7^{\prime}$ ye göre katılımcıların e-okuryazarlığa ilişkin tutum toplam puanları ile e-devlet kullanma durumu değişkeni arasında anlamlı bir farklılığın olmadığı görülmektedir $\left[\mathrm{t}_{(905)}=1,888 ; \mathrm{p}>, 05\right]$. E-devlet kullanan öğrencilerin e-okuryazarlığa ilişkin tutum puanları ortalaması $\left(\bar{X}_{=51,59)}\right.$ iken, kullanmayanların e-okuryazarlığa ilişkin tutum puanları ortalaması aritmetik ortalaması $\left(\bar{X}_{=49,86}\right)^{\prime}$ dır. Aradaki sayısal fark istatistiksel açıdan anlamlı bir farklılık oluşturmamaktadır. Bu bulgu katılımcıların e-devlet kullanma durumlarının e-okuryazarlığa yönelik tutumlarında herhangi bir farklılaşmaya sebep olmadığı şeklinde yorumlanabilir.

\section{Tablo 8.}

Katılımcıların E-okuryazarlı̆̆a İlişkin Tutumlarının İternette Geçirilen Zaman DeğişkenineGöre Farklılı̆̆ı Tek Yönlü Varyans Analizi (ANOVA) Sonuçları

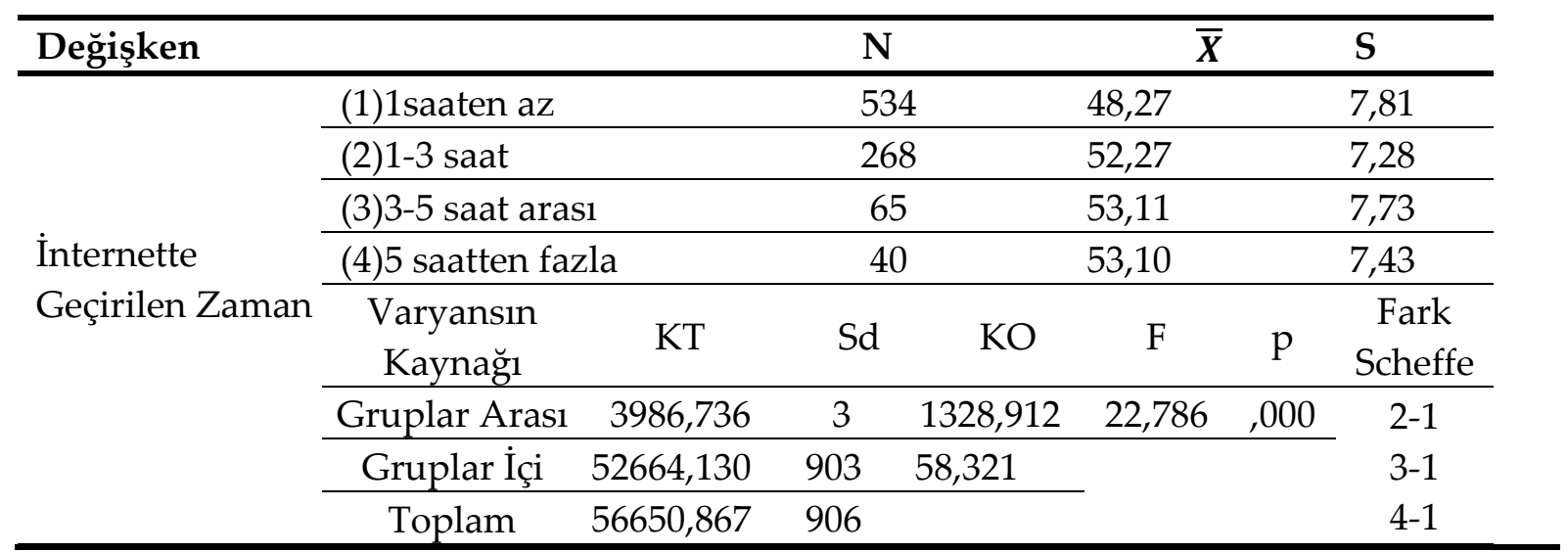

Tablo 8'e göre katılımcıların e-okuryazarlığa ilişkin tutum toplam puanları ile internette geçirilen zaman değişkeni arasında anlamlı bir farklılığın olduğu görülmektedir $\left[\mathrm{F}_{(3-}\right.$ 903) $=22,786 ; p<, 05]$. Bu farklılığın hangi gruplar arasında olduğunu öğrenmek için Scheffeçoklu karşılaştırma testi yapılmıştır. Bu sonuçlara göre internette 1 saatten az zaman geçiren katılımcıların e-okuryazarlığa ilişkin tutum toplam puanları ortalaması $(\overline{\boldsymbol{X}}=48,27)$ ile internette 1-3 saat arası zaman geçiren katılımcıların e-okuryazarlığa ilişkin tutum toplam puanları ortalaması $(\overline{\boldsymbol{X}}=52,27), 3-5$ saat arası zaman geçiren katılımcıların e-okuryazarlığa ilişkin tutum toplam puanları ortalaması $(\overline{\boldsymbol{X}}=53,10), 5$ saatten fazla zaman geçiren katılımcıların eokuryazarlığa ilişkin tutum toplam puanları ortalaması $(\bar{X}=53,10)$ arasında internette $1-3$ saat 
arası, 3-5 saat arası ve 5 saatten fazla zaman geçiren katılımcıların lehine anlamlı farklılık bulunmuştur. Bu bulgu; katılımcların internette geçirdikleri zamanın arttıkça onların eokuryazarlığa ilişkin tutumlarının da daha olumlu olduğu şeklinde yorumlanabilir.

\section{Tablo 9.}

Katılımcıların E-okuryazarlığa İlişkin Tutumlarının Akıllı Telefona Sahip Olma Değişkenine Göre ttesti Sonuçları

\begin{tabular}{|c|c|c|c|c|c|c|}
\hline $\begin{array}{l}\text { Akıllı Telefonunuz } \\
\text { Var mı? }\end{array}$ & $\mathbf{N}$ & $\bar{X}$ & $S$ & sd & $\mathbf{t}$ & $\mathrm{p}$ \\
\hline Evet & 437 & 51,70 & 7,53 & \multirow{2}{*}{905} & \multirow{2}{*}{6,341} & \multirow{2}{*}{,000 } \\
\hline Hayır & 470 & 48,44 & 7,93 & & & \\
\hline
\end{tabular}

Tablo 9'a göre katılımcıların e-okuryazarlığa ilişkin tutum toplam puanları ile akıllı telefona sahip olma değişkeni arasında anlamlı bir farklılığın olduğu görülmektedir [ $\left.\mathrm{t}_{(905)}=6,341 ; \mathrm{p}<, 05\right]$. Akıllı telefonu olan öğrencilerin e-okuryazarlığa ilişkin tutum puanları ortalaması $\left(\bar{X}_{=51,70)}\right.$ iken, olmayanların e-okuryazarlığa ilişkin tutum puanları ortalaması aritmetik ortalaması $\left(\bar{X}_{=48,44}\right)^{\prime}$ dür. Aradaki fark istatistiksel açıdan anlamlıdır. Bu bulgu katılımcıların akıllı telefona sahip olma durumlarının e-okuryazarlığa ilişkin tutumlarında farklılaşmaya sebep olduğu şeklinde yani akıllı telefonu olan öğrencilerin e-okuryazarlığa ilişkin tutumlarının olmayanlara göre daha olumlu olduğu şeklinde yorumlanabilir.

Tablo 10.

Katılımcıların E-okuryazarlı̆̆a İlişkin Tutumlarının İnterneti Kullanma Amacı Değişkenine Göre Farklılı̆̆ı için Welch Testi Sonuçları

\begin{tabular}{|c|c|c|c|c|c|c|}
\hline Değişken & & & & $\mathbf{N}$ & $\overline{\bar{X}}$ & $S$ \\
\hline \multirow{10}{*}{$\begin{array}{l}\text { İnterneti Kullanma } \\
\text { Amacı }\end{array}$} & \multicolumn{3}{|c|}{ (1) Oyun } & 144 & 50,85 & 7,53 \\
\hline & \multicolumn{3}{|c|}{ (2) Sosyal medya } & 155 & 53,17 & 6,55 \\
\hline & \multicolumn{3}{|l|}{ (3) Bilgi } & 309 & 50,48 & 7,90 \\
\hline & \multicolumn{3}{|c|}{ (4) Ödev } & 299 & 47,48 & 8,00 \\
\hline & & İstatistik & sd1 & $\mathrm{sd} 2$ & $\mathrm{p}$ & $\begin{array}{l}\text { Fark } \\
\text { Tamhane }\end{array}$ \\
\hline & \multirow{5}{*}{ Welch } & \multirow{5}{*}{22,495} & \multirow{5}{*}{3} & \multirow{5}{*}{417,543} & \multirow{5}{*}{,000 } & $1-4$ \\
\hline & & & & & & $2-1$ \\
\hline & & & & & & $2-3$ \\
\hline & & & & & & $2-4$ \\
\hline & & & & & & $3-4$ \\
\hline
\end{tabular}

Tablo 10'a göre katılımcıların e-okuryazarlığa ilişkin tutum toplam puanları ile interneti kullanma amacı değişkeni arasında anlamlı bir farklılığın olduğu görülmektedir $\left[\mathrm{F}_{(\text {welch })=}\right.$ 22,495; $\mathrm{p}<, 05]$. Bu farklılığın hangi gruplar arasında olduğunu öğrenmek için Tamhane testi yapılmıştır. Bu sonuçlara göre interneti oyun amacıyla kullanan katılımcıların e-okuryazarlığa ilişkin tutum toplam puanları ortalaması $(\overline{\boldsymbol{X}}=50,85)$ ile ödev amacıyla kullanan katılımcıların e-okuryazarlığa ilişkin tutum toplam puanları ortalaması $(\bar{X}=47,48)$ arasında oyun amacıyla kullananların lehine; interneti sosyal medya amacıyla kullanan katılımcıların e-okuryazarlığa 
ilişkin tutum toplam puanları ortalaması $(\overline{\boldsymbol{X}}=53,17)$ ile interneti oyun amacıyla kullanan katılımcıların e-okuryazarlığa ilişkin tutum toplam puanları ortalaması $(\bar{X}=50,85)$, interneti bilgi amacıyla kullanan katılımcıların e-okuryazarlığa ilişkin tutum toplam puanları ortalaması $(\overline{\boldsymbol{X}}=50,48)$, interneti ödev amacıyla kullanan katılımcıların e-okuryazarlığa ilişkin tutum toplam puanları ortalaması $(\bar{X}=47,48)$ arasında, interneti sosyal medya amaciyla kullananların lehine; interneti bilgi amacıyla kullanan katılımcılar ile interneti ödev amacıyla kullanan katılımcıların arasında ise bilgi amacıyla kullanan katılımcıların lehine anlamlı farklılık bulunmuştur. Bu bulgu; katılımcıların interneti kullanma amaçlarının onların eokuryazarlığa ilişkin tutumlarında etkili olduğu şeklinde yorumlanabilir. Diğer bir deyişle, interneti sosyal medya için kullanan katılımcıların interneti oyun, bilgi ve ödev amacıyla kullananlara göre; oyun ve bilgi için kullananların da ödev için kullananlara göreeokuryazarlığa ilişkin tutumlarının daha olumlu olduğu söylenebilir.

\section{SONUÇ, TARTIŞMA VE ÖNERILER}

Araştırmanın sonuçlarına baktığımızda katılımcıların e-okuryazarlığa ilişkin tutumları cinsiyet değişkenine göre anlamlı bir farklılık göstermektedir. Diğer bir deyişle erkek öğrencilerin kız öğrencilere göre e-okuryazarlık tutumlarının daha yüksek olduğu söylenebilir. Bu durum erkek öğrencilerin bilgisayarla ve internet ortamında daha fazla zaman geçiriyor olmalarıyla açıklanabilir. Bu durum Göldağ ve Kanat'ın (2018) yaptıkları çalışmada erkek öğrencilerin dijital okuryazarlık düzeylerinin kız öğrencilere göre daha yüksek olduğu sonucu ve Gülmez'in (2015) yaptığı araştırmada katılımcıların internet öz-yeterlik düzeyleri ile cinsiyetleri arasında farklılaşma saptandığı ve bu farklılaşmanın erkeklerin lehine olduğu yönündeki sonuçlarlarla örtüşürken, Kozan (2018) tarafından yapılan çalışmada katılımcıların dijital okuryazarlık düzeylerinin cinsiyet değişkenine göre farklılık göstermemesine yönelik sonuçla ise farklılaşmaktadır.

Araştırmada katılımcıların e-okuryazarlığa ilişkin tutumlarının sınıf düzeylerine göre anlamlı bir farklılık gösterdiği ve bu farklılığın da 8. sınıflar lehine olduğu sonucuna ulaşılmıştır. Bu durum katılımcıların küçük yaşlardan itibaren telefon, bilgisayar gibi elektronik cihazlarla tanışmaları ve yaşları ilerledikçe de bu cihazları daha etkili ve bilinçli kullanıyor olmalarıyla açıklanabilir. Öte yandan bu sonuç yapılan araştırmalarda (Kozan, 2018; Ulusay, 2018) katılımcıların dijital okuryazarlık düzeylerinin öğrenim gördükleri sınıf düzeyine göre farklılık gösterdiğini ortaya koyan çalışmaların sonuçlarıyla da örtüşmektedir.

Araştırmanın bir başka sonucunda ise katılımcıların e-okuryazarlığa ilişkin tutumlarının bilgisayarlarının, akıllı telefonlarının ve evlerinde internet bağlantısının olma durumu değişkenine göre farklılık gösterip göstermediği test edilmiş ve katılımcıların e-okuryazarlığa ilişkin tutumları ile bilgisayara, akıllı telefona ve evde internet bağlantısına sahip olma durumları arasında bilgisayarı, akıllı telefonu ve internet bağlantısı olan katılımcıların lehine farklılık saptanmıştır. Bu farklılık hem bilgisayarı ve akıllı telefonu hem de internet bağlantıları olan katılımcıların hem bilgisayarla ve akıllı telefonla hem de onun argümanları ile daha fazla vakit geçiriyor olmalarıyla açıklanabilir. Çünkü bireyler internet ağı, bilgisayar ve akıllı telefon sayesinde e-okuryazarlık becerilerini kolaylıkla geliştirebilmektedir. Örneğin bir metne ses, animasyon, resim eklenmesinde, metnin sanal ortamda başkalarıyla paylaşılmasında ya da bir bilgiye ulaşmada internet ağı, akıllı telefon ve bilgisayar etkili olmaktadır (Gumbo, Ntšekhe, \&Terzoli, 2014). Bu etkililiğin de bireylerin eokuryazarlıklarında olumlu farklılaşmalara sebep olabileceği söylenebilir. Araştırmadaki bu 
sonuç Göldağ ve Kanat'ın (2018) yaptıkları çalışmada, bilgisayara sahip olan öğrencilerin dijital okuryazarlık düzeylerinin bilgisayara sahip olmayan öğrencilere göre daha yüksek olduğu yönündeki sonuçla benzerlik gösterirken, Kozan (2018) tarafından yapılan araştırmadaki katılımcıların dijital okuryazarlık düzeylerinin kişisel bilgisayara sahip olma durumlarına göre anlamlı bir farklılık göstermediği yönündeki sonuçla farklılaşmaktadır.

Öte yandan araştırmada katılımcıların e-okuryazarlığa yönelik tutumlarında mail adresine sahip olma durumlarının herhangi bir farklılaşmaya sebep olup olmadığı araştırılmış ve kişisel mail adresine sahip olanların e-okuryazarlığa yönelik tutumlarının olmayanlara oranla daha olumlu olduğu sonucuna ulaşılmıştır. Bu sonuç mail adresi sayesinde öğrencilerin karşılıklı iletişim kurabildiklerinin, elektronik ortamlarda kolaylıkla metinler yazıp paylaşabildiklerinin ve elektronik ortamın birçok özelliği hakkında bilgi sahibi olduklarının, dolaysıyla da bu sayılanlar mail adresine sahip olmanın kişinin e-okuryazarlık tutumlarını olumlu yönde etkilediğinin kanıtı sayılabilir. Bu çalışmada kişinin mail adresine sahip olması, e-okuryazarlığa ilişkin tutumda farklılaşma sağlayan bir etken olarak görülse de Göldağ ve Kanat (2018) tarafından yapılan çalışmada katılımcıların bir sosyal medya hesabına sahip olmalarının onların dijital okuryazarlık düzeylerinde herhangi bir farklılaşmaya neden olmadığ1 yönündeki sonuçla örtüşmemektedir.

Araştırmanın bir diğer sonucunda ise katılımcıların e-okuryazarlığa ilişkin tutumları internetten alışveriş yapma değişkenine göre farklılık gösterdiğine yöneliktir. İnternetten alışveriş yapan katılımcılar yapmayanlara göre e-okuryazarlığa ilişkin tutumları daha olumludur. Bu durum internet üzerinden alışveriş yapan katılımcıların bu alanda birçok bilgiyi de öğrenmiş olmalarıyla ve kolaylıkla interneti kullanabilmeleriyle ona aşina olmalarıyla açıklanabilir.

Katılımcıların e-okuryazarlığa ilişkin tutumlarının e-devlet kullanma değişkenine göre farklılık gösterip göstermediğine yönelik sonuca baktı̆̆ımızda ise e-devlet kullanmanın eokuryazarlığa ilişkin tutumda herhangi bir farklılaşmaya neden olmadığı görülmektedir. Bu durumun, e-devlet şifresinin 15 yaşını dolduran vatandaşlar tarafından alınıyor ve sağladığ hizmetlerin ise yine yetişkinlere yönelik olmasından kaynaklandığı söylenebilir. Ayrıca bulgulara baktığımızda e-devlet kullanan katılımcıların varlığı, onların e-devleti velileri aracılığıyla kullandıklarını akıllara getirmektedir.

E-okuryazarlığa ilişkin katılımcı tutumlarının internette geçirilen zaman değişkenine göre farklılık gösterip göstermediğine yönelik sonuca baktığımızda katılımcıların internette geçirdikleri zaman arttıkça onların e-okuryazarlığa ilişkin tutumlarının da daha olumlu olduğuna yönelik sonuca ulaşılmıştır. Bu durum bireylerin internette fazla zaman geçirmelerinin, onların e-okuryazarlık becerilerini daha etkili kullanmalarına, elektronik ortamlardan daha çok haberdar olmalarına ve bu doğrultuda tutumlarının da olumlu manada daha da artmasına imkân sağlayabilir. Çünkü bireyler internette ne kadar çok zaman geçirirse ister istemez elektronik ortamın birçok becerisini kazanır hale gelmektedirler. Çetin'in (2016) yaptığı araştırmada internet kullanım sıklığının dijital okuryazarlığı olumlu yönde etkilediği sonucu bu araştırmanın sonucuyla dolaylı olarak örtüşmekteyken, yapılan bazı araştırmalarda (Kozan, 2018; Göldağ ve Kanat, 2018) bireylerin internette geçirdikleri sürenin dijital okuryazarlık düzeylerini herhangi bir şekilde etkilemediği sonucuna ulaşılmıştır.

Son olarak araştırmada e-okuryazarlığa ilişkin katılımcı tutumlarının interneti kullanma amacına göre farklılık gösterip göstermediğine yönelik sonuca baktığımızda katılımcıların interneti kullanma amaçlarının onların e-okuryazarlığa ilişkin tutumlarında farklılaşmaya 
sebep olduğu sonucuna ulaşılmıştır. Bu sonuçlara göre interneti sosyal medya için kullanan katılımcıların interneti oyun, bilgi ve ödev amacıyla kullananlara göre; oyun ve bilgi için kullananların da ödev için kullananlara göre e-okuryazarlığa ilişkin tutumlarının daha olumlu olduğu söylenebilir. Bunlardan yola çıkarak interneti oyun amacıyla, kullanan bireyler elektronik ortamda daha fazla zaman geçirecekleri için bu sayede e-okuryazarlık becerilerini daha kolay kazanabiliyor olabilirler. Bu durum da onların tutumlarını etkileyebilir. Öte yandan sosyal medyayı kullanan öğrencilerin interneti bilgi ve ödev amacıyla kullanan öğrencilere göre metin yazma, iletişim kurma ve daha birçok elektronik beceriyi kolaylıkla kullanabilecekleri için e-okuryazarlığa ilişkin tutumları da daha olumlu şekillenmiş denebilir. $\mathrm{Bu}$ durum Aslan ve Yazıcı'nın (2016) yaptığı araştırmada değindikleriyle benzerlik göstermektedir. Çalışmada çocukların internet kullanım yaşlarının giderek düştüğü, internet kullanım sürelerinin ise yükseldiği ve çocukların internette gerçekleştirdikleri etkinliklerde eğlence amaçı kullanımın arttığı, özellikle sosyal ağ kullanma, çevrimiçi film veya video klip izleme gibi etkinliklerde bir artış olduğu ve çocukların, gençlerin interneti özellikle sosyal ağlar için kullandıkları belirtilmektedir. Ayrıca Acar (2016) tarafından yapılan araştırmada, bireylerin arkadaş çevreleriyle oynadıkları oyunların teknoloji yani bilgisayar içerikli oyunlar olması bilgisayar okuryazarlık düzeylerini arttırdığına yönelik sonuç mevcut araştırmanın bu sonucuyla dolaylı olarak örtüşmektedir.

Yaşadığımız yüzyılda, okuryazarlık çeşitleri arasında en gerekli olanlardan biri olarak gösterilen e-okuryazarlık, teknolojik gelişmelerden etkilenmekte ve bu etkilenme de toplumsal değişmeye hız kazandırmaktadır. Toplumsal öğrenmenin temelini oluşturan bu gelişmeler, bilginin bulunduğu ortamı giderek daha karmaşık hale getirmektedir. Ancak bu durum gelecek kuşakları yeterince bilgi, beceri, değer kazandırarak toplumun beklentisi doğrultusunda yetiştirmeyi amaç edinmiş eğitimcilerin ve bilgiye talip olan yeni kuşağın enformasyon çevresinde yerlerini almalarına engel olmamalı bilakis bu durum formal öğrenme sürecinin bir parçası olarak görülmelidir (Nayak, Nayak ve Murgod, 2006). Bununla beraber alanyazın incelendiğinde e-okuryazarlığa yönelik özellikle ortaokul düzeyinde yeterli sayıda çalışmanın olmadığı görülmektedir. Bu sayının yeterli seviyelere ulaşabilmesi için farklı yöntemler ve desenler esas alınarak daha derinlemesine bilgiler sunacak çeşitli seviye ve çalışma gruplarında e-okuryazarlığa yönelik araştırmaların yapılması önerilmektedir. 


\section{KAYNAKÇA}

Acar, D. (2016). Ortaokul öğrencilerinin bilgisayar okuryazarlığının matematik okuryazarlı̆̆ın etkisi. (Yüksek lisans tezi). Fırat Üniversitesi. https://tez.yok.gov.tr sayfasından erişilmiştir.

Altun, A. (2003). E-okuryazarlık. Milli Eğitim Dergisi, Sayı. 158.

Altun, A. (2005). Gelişen teknolojiler ve yeni okuryazarlıklar. Ankara: Anı

Aslan, E. \& Yazıcı, A. (2016). Üniversite öğrencilerinde internet bağımlılığı ve ilişkili sosyodemografik faktör. Klinik Psikiyatri, 19, 109-117.

Aşıcı, M. (2009). Kişisel ve sosyal bir değer olarak okuryazarlık. Değerler Eğitimi Dergisi, 17(7), 9-26.

Aytaş, G., \& Kaplan, K. (2017). Medya okuryazarlığı bağlamında yeni okuryazarlıklar. Ahi Evran Üniversitesi Kırşehir Ĕ̆itim Fakültesi Dergisi, 18(2), 291-310.

Büyüköztürk, Ş., Kılıç-Çakmak, E., Akgün, Ö. E., Karadeniz, Ş. \& Demirel, F. (2010). Bilimsel araştırma yöntemleri. (7. Baskı). Ankara: Pegem.

Çetin, O. (2016). Pedagojik formasyon programı ile lisans eğitimi fen bilimleri öğretmen adaylarının dijital okuryazarlık düzeylerinin incelenmesi. Erzincan Üniversitesi Ĕ̆itim Fakültesi Dergisi, 18(2), 658-685

Gilster, P. (1997). Digital Literacy. New York: Wiley Computer Publishing.

Göldağ, B. \& Kanat, S. (2018). Güzel sanatlar eğitimi alan öğrencilerin dijital okuryazarlık durumlar1. International Journal of Social Science, 70(1), 77-92. http://dx.doi.org/10.9761/ JASSS7736.

Gumbo, S., Ntšekhe, M., \& Terzoli, A. (2014). E-Literacytraining in deepruralareas: The Siyakhula Living Lab experience. Proceedings of the e-Skillsfor Knowledge Production and Innovation Conference 2014, Cape Town, South Africa, 141-154.

Gülmez, T. (2015). Fen bilgisi öğretmen adaylarının internet özyeterlik düzeyleri ile bilgi okuryazarlık özyeterlikleri arasındaki ilişki. (Yüksek lisans tezi). Kahraman Maraş Sütçü İmam Üniversitesi. https://tez.yok.gov.tr sayfasından erişilmiştir.

Güneş, F. (1994). Okur yazarlık kavramı ve düzeyleri. Ankara Üniversitesi Dergisi, 27(2), 500507.

Higher Education Funding Council for England (HEFCE), (2004). Consultation on HEFCE elearning strategy. https://itlab.us/learning/hefce e learning.pdf adresinden erişildi.

Karasar, N. (2015). Bilimsel araştırma yöntemi. (28. Baskı). Ankara: Nobel.

Karatekin, K. (2013). Çevre okuryazarlığı. Gençtürk, E., \& Karatekin, K. (Ed.), Sosyal bilgiler için çoklu okuryazarlıklar içinde (s.46-73). (3. Baskı). Ankara: Pegem. 
Kellner, D. (2001). New technologies/ New literacies: Recon structing education for the new millennium. International Journal of Technology and Design Education, 11, pp.67-81.

Kılcan, B. \& Çepni, O. (2017). E-okuryazarlık ve sosyal bilgiler. Akdağ, H., \&Turan, R. (Ed.), Sosyalbilgileröğretiminde yeni yaklaşımlar III (1. Baskı) içinde (s.356-388). Ankara: Pegem.

Kılcan, B. \& Gülbudak, B. (2019). E-okuryazarlığa yönelik tutum ölçeğinin geliştirilmesi geçerli ve güvenirlik çalışmaları. Ahmet Keleşoğlu Eğitim Fakültesi Dergisi, 1(1), 60-71.

Kozan, M. (2018). Bilgisayar ve öğretim teknolojileri eğitimi bölümüm öğretmen adaylarının dijital okuryazarlık düzeyleri ve siber zorbalı̆̆a ilişkin duyarlılıklarının incelenmesi. (Yüksek lisans tezi). Fırat Üniversitesi. https://tez.yok.gov.tr sayfasından erişilmiştir.

Milli Eğitim Bakanlığı [MEB], (2018). Sosyal bilgiler dersi öğretim programı. http://mufredat.meb.gov.tr/ sayfasından erişilmiştir.

Nayak, V. D., Nayak R. R. \& Murgod, S. G. (2006). E-information literacy: An overview, 4th International Convention CALIBER, Gulbarga, 2-4 February, INFLIBNET Centre, Ahmedabad. http://ir.inflibnet.ac.in:8080/ir/bitstream/1944/1183/1/35.pdf

Reinking, D., McKenna, M., Labbo, L., \& Kieffer, R.D. (Eds.). (1997). Literacy for the 21st century: Technological transformations in a post-typographical world. Mahwah, NJ: Erlbaum.

Sakallı, H. (2015). Sını öğretmeni adaylarının dijital vatandaşlık düzeyleri ile siber zorbalık eğilimleri arasındaki ilişkinin incelenmesi. (Yüksek lisan tezi). Adnan Menderes Üniversitesi. https://tez.yok.gov.tr sayfasından erişilmiştir.

Tuman, M. (1994). Word Perfect: Literacy in Computer Age, London-Philadelphia: Falmer.

Ulusoy, A. (2018). Dijital medya okuryazarlı̆̆l gereksinimler ve yenilikçi uygulamalar üzerine bir inceleme. (Doktora tezi). Erciyes Üniversitesi. https://tez.yok.gov.tr sayfasından erişilmiştir.

Yılmaz, B. (1989). Okuryazarlık ve okuma alışkanlığı üzerine. Türk Kütüphaneciliğii, 3(1), 48-53.

Yiğit, E. Ö. (2013). Teknoloji okuryazarlı̆̆ı. Gençtürk, E., \& Karatekin, K. (Ed.), Sosyal bilgiler için çoklu okuryazarlıklar (3. Baskı)içinde (s.256-289). Ankara: Pegem. 


\section{Extended Summary}

The research was carried out to determine the attitudes of secondary school students towards e-literacy in terms of various variables. For this purpose, the survey method was used in the research. Karasar (2015, p. 77) defines this method as the evaluation of something that is the topic of the research under the existing conditions without any influence.

The participant group of the research consisted of 907 (Male 456- Female 451) secondary school students selected in accordance with the sampling method, which is easily accessible among the purposeful sampling methods in Kulu district of Konya during the 2017-2018 academic year. Easy accessibility in sample selection can be explained through the fact that the first researcher was working in the specified district and he knew the administrators and teachers of the schools where the practice was carried out.

In the study, as a data collection tool, the personal information form to determine demographic information about the participants and the E-Literacy Attitude Scale (EYTO) developed by Kilcan and Gülbudak (2019) were used. The scale used consisted of 21 items in the 3-point Likert type and it consisted of a single factor. The single factor of the scale explains $30.97 \%$ of the total variance of the scale, and the factor loads of the items included here vary between 0.45 and 0.71 .

At this stage, first of all the data collection tool was distributed to the participants and information was provided about the purpose of the research. Later on, the participants were informed by reading the instructions in the data collection tool on how to do carry out study. After the practice, 93 forms with incomplete markings and blank ones were identified out of 1000 forms received from the participants and they were excluded from the scope of the research, thus 907 forms constituted the data set of the research.

SPSS package program was used to analyze the data set obtained from the participants. As a result of the statistical analysis, $t$ test and one-way Variance Analysis were used for independent groups when the data displayed normal distribution, and Welch test was used when the data did not display normal distribution. Scheffe and Tamhane tests, which are among the post hoc tests, were used to determine the significance of the variables with meaning differences.

Considering the findings and results of the research; a significant difference was found in favor of male students in the average of e-literacy attitude scores of students according to gender. This can be explained by the fact that male students spend more time with computers and in the internet environment. It was observed that as the grade levels of the students increased, there was a positive increase in e-literacy attitudes. This situation can be explained by the fact that the participants got to know electronic devices such as phones and computers at young ages and that they use them more effectively and consciously as they get older.

In addition, differences were observed between the students who had a computer at home, personal mail address and internet connection, and a smart phone and those who did not have them, and it was determined that these students' e-literacy attitudes increased positively. This difference can be explained by the fact that the participants with both computer and smart phone and internet connections spend more time with both computer and smart phone and its arguments. Because individuals can easily improve their e-literacy skills thanks to the internet network, computer and smart phone. It was observed that there was no difference in students' attitudes towards e-literacy according to their use of e-state. As they spent more time 
on the internet, students' attitudes towards e-literacy have also been found to be positive. The fact that individuals spend more time on the Internet may enable them to use their e-literacy skills more effectively, to be more aware of electronic environments, and to increase their attitudes in this sense in a positive way. Because as individuals spend more time on the internet, they acquire many skills of the electronic environment. According to the purpose of the internet use it has been found out that the participants who use the internet for social media have more positive attitude towards e-literacy compared to those who use the internet for games, information and homework; the participants who use it for games and information have more positive attitudes towards e-literacy than those who use it for homework. From this point of view, individuals who use the internet for game might gain e-literacy skills more easily because they will spend more time in electronic environment. This situation may affect their attitudes. On the other hand, it can be said that the attitudes of students using social media towards e-literacy might have been shaped more positively as they can easily use text writing, communication and many other electronic skills. 